\title{
FORMAÇÃO DE PROFESSORES ÀS AVESSAS: UM OLHAR SOBRE A FORMAÇÃO CONCEITUAL EM ALUNOS COM DEFICIÊNCIA INTELECTUAL NAS FASES INICIAIS
}

\author{
TRAINING OF ADVISORY TEACHERS: \\ A LOOK AT CONCEPTUAL TRAINING IN STUDENTS \\ WITH INTELLECTUAL DISABILITIES IN THE INITIAL PHASES
}

\author{
CORRÊA, Roberta Pires ${ }^{1}$ \\ ARAÚJO, Daniele Francisco de ${ }^{2}$ \\ CAMPOS, Érica Costa Vliese Zicht| ${ }^{3}$
}

\begin{abstract}
Resumo
O artigo discute a formação de professores para atuar com alunos com deficiência intelectual e a importância da formação de conceitos para a aprendizagem dentro da perspectiva históricocultural de Vigotski. Para tanto, conta com os dados de três dissertações de mestrado desenvolvidas no projeto de pesquisa "A escolarização de alunos com deficiência intelectual: políticas públicas, processos cognitivos e avaliação da aprendizagem", com apoio financeiro do Programa Observatório da Educação da CAPES, desenvolvido na região da Baixada Fluminense/RJ. Metodologicamente, as pesquisas de campo foram de cunho qualitativo, estudo de caso e pesquisa-ação colaborativa. Entre os principais resultados, evidenciamos as dificuldades enfrentadas pelos professores em sua prática pedagógica em fornecer subsídios para que os alunos com deficiência intelectual se apropriem dos conhecimentos científicos no ambiente escolar. Contudo, os dados também evidenciaram possibilidades para que esses alunos tenham acesso aos conhecimentos historicamente construídos e uma delas é a formação continuada de professores baseada na perspectiva histórico-cultural.
\end{abstract}

PalAVRAS-CHAVE: Formação de professores; processos de ensino e aprendizagem; formação de conceitos; deficiência intelectual; perspectiva histórico-cultural.

1 Fundação Oswaldo Cruz - Fiocruz. Rio de Janeiro, RJ, Brasil. Secretaria Municipal de Educação do Rio de Janeiro - SME/RJ. Rio de Janeiro, RJ, Brasil. ORCID: http://orcid.org/0000-0002-8207-4438 e-mail: robertacorrea.inclusao@gmail.com

2 Secretaria Municipal de Educação do Rio de Janeiro - SME/RJ. Rio de Janeiro, RJ, Brasil. ORCID: https://orcid.org/0000-0002-5479-8391 e-mail: dany_araujo100@hotmail.com

3 Pontifícia Universidade Católica do Rio de Janeiro - PUC-RJ / Programa de Pós-Graduação em Educação. Rio de Janeiro, RJ, Brasil. Prefeitura Municipal de Nova Iguaçu. Nova Iguaçu, RJ, Brasil. Prefeitura Municipal de Duque de Caxias. Duque de Caxias, RJ, Brasil. ORCID: https://orcid.org/0000-0001-9379-7319 e-mail: ericavliese@hotmail.com 
DOI: $10.12957 /$ e-mosaicos.2021.51350

\section{ABSTRACT}

The article discusses the training of teachers to work with students with intellectual disabilities and the importance of the formation of concepts for learning within the historical-cultural perspective of Vigotski. To this end, it relies on data from three master's dissertations developed in the research project "The schooling of students with intellectual disabilities: public policies, cognitive processes and learning assessment", with financial support from the CAPES Education Observatory Program, developed at Baixada Fluminense region / RJ. Methodologically, the field research was qualitative, case study and collaborative action research. Among the main results we highlight the difficulties faced by teachers in their pedagogical practice in providing subsidies for students with intellectual disabilities to take advantage of scientific knowledge in the school environment. However, the data also showed possibilities for these students to have access to historically constructed knowledge and one of them is the continuing formation of teachers based on the historical-cultural perspective.

KEYWORDS: Teacher training; teaching and learning processes; concept formation; intellectual disability; historical-cultural perspective.

\section{INTRODUÇÃO}

Desde a Lei de Diretrizes de Bases da Educação Nacional (BRASIL, 1996) que a legislação brasileira anseia por uma formação inicial de professores da Educação Básica em nível superior (BRASIL, 1996; 2002; 2008; 2014; 2015; 2017; 2018). Atualmente, para início do exercício na docência o profissional pode ser formado na Modalidade Normal/Magistério, em nível médio; por cursos de licenciatura e por complementação pedagógica que atende graduados, porém não licenciados.

Em 2015 tivemos as contribuições das Diretrizes Curriculares Nacionais para a Formação Inicial em Nível Superior (cursos de licenciatura, cursos de formação pedagógica para graduados e cursos de segunda licenciatura) e para a Formação Continuada (BRASIL, 2015). Esse documento definiu "princípios, fundamentos, dinâmica formativa e procedimentos a serem observados nas políticas, na gestão e nos programas e cursos de formação, bem como no planejamento, nos processos de avaliação e de regulação das instituições de educação" (BRASIL, 2015: Artigo 1º).

Trazendo para o contexto da Educação Especial, pesquisas evidenciaram dificuldades docentes em se trabalhar com seus alunos público-alvo, sobretudo, pela falta de formação específica na área (KOBAYASHI, LAPLANE, 2010; KASSAR, RODRIGUES, LEIJOTO, 2011; PLETSCH, 2014; MENDES et al, 2015). 
DOI: $10.12957 / \mathrm{e}-\mathrm{mosaicos} .2021 .51350$

Nos dispositivos legais, ainda não existe um consenso sobre a formação para o professor que vai atuar na Educação Especial, o que traz o paradigma de por um lado permitir autonomia aos cursos de formações de professores em seus currículos, mas pelo outro não contemplarem qualitativamente conteúdos que valorizem os processos de ensino e aprendizagem diferenciados para os alunos da educação especial.

Ademais, atualmente a LIBRAS $^{4}$ é a única disciplina sobre Educação Especial obrigatória no currículo de todos os cursos de licenciaturas (BRASIL, 2002a: Artigo $4^{\circ}$ ). Para além, as diretrizes indicam a necessidade de currículos que contemplem a uma educação inclusiva diante da diversidade (BRASIL, 2015), o que não necessariamente implica especificamente em uma disciplina de educação especial, por exemplo.

Compreendemos que a formação inicial ainda não contempla as demandas da escola e dos alunos público-alvo da educação especial, "nem quando se considera professores supostamente 'especializados', nem na formação de professores regentes do ensino comum" (MENDES et al, 2015: 159). E é a partir desse ponto que entra em questão a formação continuada de professores, pois compreender como o aluno aprende é fundamental, sobretudo como aprendem os alunos público-alvo da educação especial e, principalmente, alunos como deficiência intelectual que apresentam um ritmo mais lento de aprendizagem, com dificuldades de atenção, abstração, memorização e demais processos psicológicos superiores.

Para que uma prática pedagógica seja de fato eficiente, além dos outros fatores como estrutura e acessibilidade, os professores precisam uma de formação adequada. Algo que os valorize e que acima de tudo, contemple a aprendizagem e desenvolvimento dos alunos.

\section{FUNDAMENTAÇÃO TEÓRICA}

A perspectiva histórico-cultural de Vigotski reflete o entrelaçamento entre o individual e o coletivo em que há uma contínua transformação nas interações sociais, compreendendo que a aprendizagem propulsiona o desenvolvimento. É na escola que as formas mais elementares de pensamento vão dando lugar às formas mais superiores, através do ensino, de intervenções pedagógicas e do planejamento.

Vigotski (2010) ao analisar as formas elementares e superiores, remete-se a um conjunto de funções estabelecidas pelo psiquismo humano. A primeira está no campo da natureza, comum aos homens e animais, enquanto a segunda corresponde a características humanas ligadas à cultura. Dessa maneira, entendemos que para o

4 Língua Brasileira de Sinais.

FORMAÇÃO DE PROFESSORES ÀS AVESSAS: UM OLHAR SOBRE A FORMAÇÃO 234 CONCEITUAL EM ALUNOS COM DEFICIÊNCIA INTELECTUAL NAS FASES INICIAIS 
DOI: $10.12957 / \mathrm{e}-\mathrm{mosaicos} .2021 .51350$

indivíduo elaborar conceitualmente o pensamento, suas funções psicológicas superiores precisam estar desenvolvidas, pois, a cada conceito que o indivíduo se apropria, ele reelabora os seus conhecimentos já adquiridos.

Ao pensarmos a aprendizagem de alunos com deficiência intelectual, nos reportamos a um público-alvo que utiliza estratégias de elaboração de pensamentos específicas que, para se desenvolverem academicamente, precisam de intervenções pedagógicas e mediações ${ }^{5}$ de um adulto ou de uma pessoa mais experiente.

O mundo é pensado por conceitos e sua importância no processo de aprendizagem é fundamental. Os conceitos cotidianos são adquiridos no dia a dia, nas experiências práticas e nas situações informais de aprendizagem e os conceitos científicos, na escola (CORRÊA, 2016). A autora ainda acrescenta as dificuldades dos alunos com deficiência intelectual, como dificuldades na organização do pensamento e em processos de abstração e generalização, o que "requer que o professor conheça as demandas de seus alunos e, a partir deste olhar atento, propicie situações de aprendizagem que contribuam para este processo (CORRÊA, 2016: 33).

O processo da elaboração conceitual para esses alunos ocorre a partir do constante processo de mediação, que se realiza através da interação entre os indivíduos. VYGOTSKI (1996), apud MARTINS (2013) corroboram com esse pensamento na medida em que compreendem que as formas superiores de comportamento consciente deveriam acontecer nas relações sociais que o indivíduo mantém com o mundo exterior. Ademais:

O pensamento em conceitos é o meio mais adequado para conhecer a realidade porque penetra na essência interna dos objetos, já que a natureza dos mesmos não se revela na contemplação direta de um ou outro objeto isolado, senão por meio dos nexos e relações que se manifestam na dinâmica do objeto, em seu desenvolvimento vinculado a todo resto da realidade. O vínculo interno das coisas se descobre com ajuda do pensamento por conceitos, já que elaborar um conceito sobre algum objeto significa descobrir uma serie de nexos e relações do objeto dado com toda a realidade, significa incluí-lo no complexo sistema de fenômenos (VYGOTSKI, 1996, p. 79, apud MARTINS, 2013, p. 296).

Para que o indivíduo consiga conceituar, relativizar, realizar operações lógicomatemáticas ele precisa ter se apropriado das funções elementares. Segundo Souza

5 Trata-se de enfocar as significações da ação humana, os sentidos das práticas, considerando que todas as ações adquirem múltiplos significados, múltiplos sentidos, e tornam-se práticas significativas, dependendo das posições e dos modos de participação dos sujeitos nas relações (SMOLKA, 2000, p. 31). 
DOI: $10.12957 / \mathrm{e}-\mathrm{mosaicos} .2021 .51350$

(2009) as funções elementares são aquelas de natureza biológica comum entre homens e animais, como por exemplo, o reflexo. As funções superiores são aquelas produzidas no enlace entre $o$ indivíduo e a sociedade, sendo assim próprias do homem, entre elas: a capacidade de fazer cálculo, tocar um instrumento musical, ler, comparar e generalizar. Os desenvolvimentos das funções psicológicas superiores dependem da concretização das funções elementares.

Vigotski (1997) salienta que os entraves encontrados na aprendizagem e, consequentemente, na apropriação de conceitos pelos indivíduos com deficiência intelectual, não se restringem somente ao caráter orgânico, mas, sobretudo, nas condições desfavoráveis de desenvolvimento e aprendizado em que são expostos. Dessa forma, distingue a deficiência primária da deficiência secundária, em que a primeira é de ordem biológica e a segunda de ordem social. Assim, o desenvolvimento do sujeito depende da relação que o indivíduo estabelece com o meio social.

O autor foi precursor do olhar ao indivíduo pelas suas possibilidades de desenvolvimento, em outras palavras, conforme aquilo que ele é capaz de realizar sozinho (desenvolvimento real). Também contribuiu com conceitos como o de desenvolvimento potencial $^{6}$, que é o desenvolvimento que o indivíduo pode alcançar. A distância entre esses dois desenvolvimentos é chamada de Zona de Desenvolvimento Proximal (ZDP), que pode ser entendida como:

A zona de desenvolvimento proximal define aquelas funções que ainda não amadureceram, mas estão no processo de amadurecimento, funções que amadurecerão amanhã, mas que estão corretamente em um estágio embrionário. Tais funções podem ser chamadas de "botões" ou flores do desenvolvimento, em vez de serem chamadas de "frutos" do desenvolvimento (VIGOTSKI, 1978, p. 86).

Em sua observação à escolarização de crianças com deficiência e sem deficiência, apontou a necessidade da criação de estratégias para a aprendizagem de alunos com deficiência. Também acrescentou que os conceitos científicos se ancoram nos conceitos cotidianos estabelecendo uma dependência (VIGOTSKI, 2010).

6 O nível de desenvolvimento potencial se relaciona as capacidades em vias de serem construídas (KRETZSCHMAR JOENK, 2021, p.10) 
DOI: $10.12957 / \mathrm{e}-\mathrm{mosaicos} .2021 .51350$

Dito isso, consideramos como tarefa da escola ofertar condições para que todos os alunos construam formas mais elaboradas de pensamento, avançando dos conceitos cotidianos para os conceitos científicos, que são próprios do espaço escolar. Nas fases iniciais, este processo é fundamental, pois a criança é posta a formular e resolver problemas e em crianças com deficiência intelectual essa tarefa é secular, uma vez que, abstrair e generalizar são as principais barreiras orgânicas postas pela deficiência.

\section{Procedimentos metodológicos}

O presente artigo busca discutir a formação de professores para atuar com os alunos com deficiência intelectual e a importância da formação de conceitos para a aprendizagem dentro da perspectiva histórico-cultural de Vigotski. Consiste em um compilado de três pesquisas de mestrado orientadas no âmbito do Grupo de Pesquisa Observatório de Educação Especial e Inclusão Educacional (ObEE): "A formação de conceitos em alunos com deficiência intelectual: aspectos do processo de ensino e aprendizagem" (CORRÊA, 2016); "Diálogos entre o currículo e o Planejamento Educacional individualizado (PEI) na escolarização de alunos com deficiência intelectual" (CAMPOS, 2016) e "Formação continuada de professores na perspectiva da educação inclusiva na Baixada Fluminense" (ARAUJO, 2016). Cabe ressaltar que os nomes dos sujeitos são fictícios, corroborando com a ética em pesquisa.

A pesquisa de Corrêa (2016) buscou compreender a formação de conceitos em alunos com deficiência intelectual. Com os pressupostos metodológicos do estudo de caso, teve como sujeitos dois alunos com deficiência intelectual, matriculados nos anos iniciais do ensino fundamental, em escolas regulares no município de Belford Roxo/RJ. Ambos frequentavam a Sala de Recursos Multifuncionais para Atendimento Educacional Especializado. Para coleta de dados foi utilizada a observação participante com registro em diário de campo.

O trabalho de pesquisa realizado por Campos (2016) trouxe para discussão a proposta de refletir sobre como aspectos acerca de novas práticas pedagógicas, a partir da utilização do Planejamento Educacional Individualizado (PEI) ${ }^{7}$ e adequação do currículo, utilização de diferentes recursos e apoios para a aprendizagem, assim como reconhecer os alunos com deficiência em sua individualidade, podem ser um facilitador em seus processos de inclusão e escolarização. Realizada no município de Nova Iguaçu,

7 O planejamento educacional individualizado (PEI) também é conhecido como plano educacional individualizado (PEI), planejamento educacional individualizado (PEI), plano de desenvolvimento psicoeducacional individualizado (PPI), plano de desenvolvimento educacional individualizado (PDEI) (MARIN; BRAUN, 2013). Optamos pela nomenclatura planejamento por acreditarmos ser de maior abrangência para a questão tratada. 
DOI: $10.12957 / \mathrm{e}-\mathrm{mosaicos} .2021 .51350$

baseou-se nos pressupostos metodológicos da pesquisa-ação colaborativa, envolvendo a formação de professores de classe comum e sala de recursos multifuncional.

A pesquisa de Araujo (2016) buscou analisar um programa de formação continuada de professores sob a ótica da perspectiva histórico-cultural e, metodologicamente, da pesquisa-ação colaborativa. O campo de estudos foi o Curso de Extensão "Processos de ensino e aprendizagem de alunos com deficiência intelectual", desenvolvido pelo ObEE/UFRRJ e os sujeitos da pesquisa foram 100 professores da Educação Básica de sete ${ }^{8}$ municípios da Baixada Fluminense. Para a coleta de dados foram utilizados os seguintes instrumentos: registros em diário de campo, fotos e vídeos; dois questionários semiestruturados; os trabalhos de conclusão de curso, doravante denominados de projetos de intervenção e depoimentos gravados/filmados com as impressões do curso pelos participantes.

\section{APRESENTAÇÃO E DISCUSSÃO DOS RESULTADOS}

O grupo Observatório de Educação Especial e Inclusão Educacional (ObEE) vem realizando pesquisas na região da Baixada Fluminense/Estado do Rio de Janeiro, cuja realidade da Educação Especial é precária, marcada por problemas como o não recebimento ou recebimento parcial de material para compor as salas de recursos multifuncionais, a má ou ausência de formação dos professores para atuar no atendimento educacional especializado, assim como a falta de acessibilidade física e transporte adaptado (PLETSCH, 2014).

A autora ainda acrescenta que a maior parte das dificuldades pedagógicas se concentra na escolarização de alunos com deficiência intelectual e sinaliza para a falta de clareza sobre o conceito e concepções sobre essa deficiência, tanto na esfera de políticas públicas quanto no desenvolvimento de práticas que contemplem esses educandos (PLETSCH, 2014).

Diante da realidade encontrada e também como retorno às investigações realizadas, o ObEE desenvolveu uma formação continuada em educação especial na perspectiva da educação inclusiva para os professores dos municípios participantes dos projetos em parceria com o Fórum Permanente de Educação Especial da Baixada Fluminense (FPEEBF), a fim de intervir na realidade da região.

De acordo com os dados coletados, $32,7 \%$ dos professores não possuíam nenhuma formação em educação especial ou educação inclusiva, mesmo atuando diretamente com alunos com deficiência ou transtornos globais do desenvolvimento ou altas habilidades/superdotação (ARAUJO, 2016). Quanto aos professores pós-graduados

8 Belford Roxo, Duque de Caxias, Mesquita, Nilópolis, Nova Iguaçu, Queimados e São João de Meriti. 
DOI: $10.12957 / \mathrm{e}-\mathrm{mosaicos} .2021 .51350$

participantes do curso, apenas 30,90\% eram especialistas em Educação Especial, como mostra o gráfico abaixo:

FIg.1: Pós-graduação dos participantes/docentes do Programa de Formação Continuada

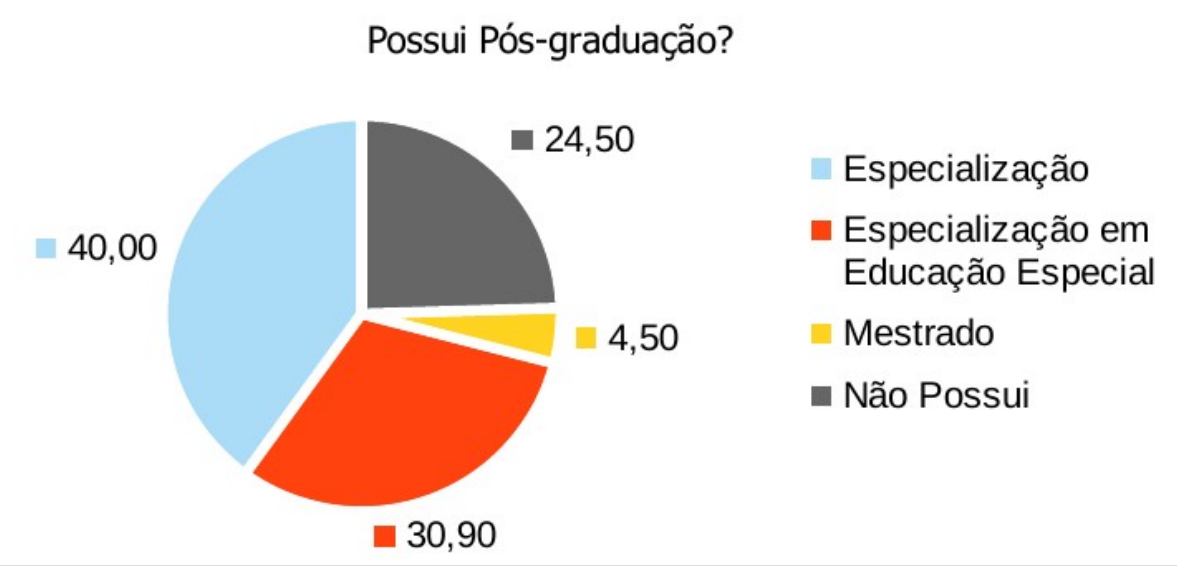

Fonte: Araujo (2016, p. 83).

Outro dado muito interessante se refere às formações continuadas em educação especial oferecidas pelos municípios da Baixada já mencionados no período entre 2012 e 2016 sintetizadas no gráfico a seguir:

Fig.2: Panorama formativo dos municípios participantes da pesquisa (2012-2016)

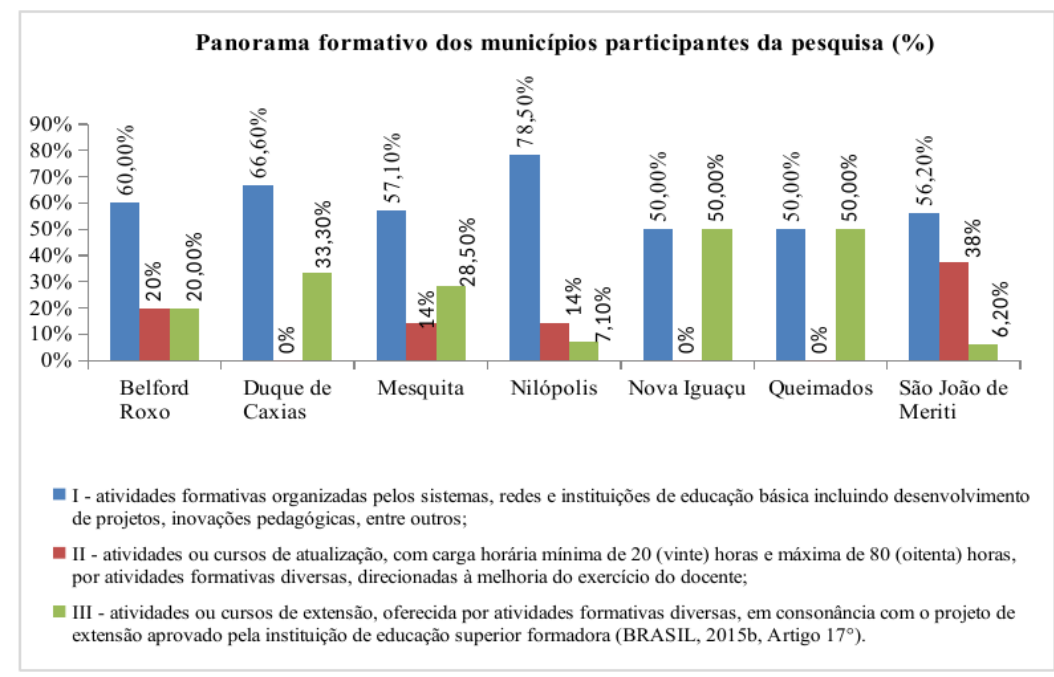

Fonte: Araújo (2016 p. 84). 
DOI: $10.12957 / \mathrm{e}-\mathrm{mosaicos} .2021 .51350$

Ressaltamos que para a sua categorização, seguimos as definições sobre formação continuada das Diretrizes Curriculares Nacionais para a Formação Inicial em Nível Superior e para a Formação Continuada (BRASIL, 2015; ARAUJO, 2016).

A maioria das formações se concentra em atividades organizadas pelas secretarias municipais de educação, sob égide das coordenadorias municipais de educação especial, como encontros, palestras ou seminários pontuais com temas. A análise de dados mostrou que são formações com foco mais teórico, sem debate aprofundado e de curtíssima duração, além de não apostarem em retornos ou devolutivas qualitativas dos participantes (ARAUJO, 2016).

Ademais, por enquanto essas formações foram realizadas em virtude de uma demanda, não contemplando todos os docentes, priorizando os professores que tinham alunos público-alvo da Educação Especial em suas turmas. Diante dessa realidade, consideramos que a realidade da Baixada Fluminense como um todo, com toda a sua precariedade no ensino e na formação inicial, não daria conta nesse momento de realizar formações que atendessem a todos os interessados, cientes de que qualquer professor possa receber em sua turma um aluno com deficiência, a qualquer momento. Entretanto compreendemos que há urgência em se repensar políticas nacionais de formação continuada de professores que possam vir a oferecer melhor suporte aos estados e municípios.

Quanto à avaliação da aprendizagem dos alunos com deficiência intelectual, os dados de Araujo (2016) mostraram que 37,87\% dos professores acreditavam no início do curso que a aprendizagem de seus alunos era insuficiente; $25,75 \%$ satisfatória; 3,03\% consideravam que 0 aluno estava na escola apenas para socialização; $1,51 \%$ afirmaram que 0 aluno não aprendia; $3,03 \%$ não responderam à pergunta e $28,78 \%$ responderam com a opção outros. Com relação às explicações dessa última resposta, os relatos se dividem em dois grupos: aprendizagem em processo e aprendizagem possível dentro das capacidades do aluno.

Para Campos (2016), a realidade que antes priorizava apenas a reprodução de conhecimentos e informações, sem levar em consideração o aluno com deficiência e suas especificidades, foi sendo substituída por momentos de reflexão sobre o processo de escolarização desses educandos, criando condições viáveis de aprendizagem e desenvolvimento, a partir da remoção de barreiras estruturais e atitudinais.

De modo a exemplificar, apresentarmos os dados da pesquisa de Corrêa (2016) em que nos reportamos o olhar para a formação dos professores e aprendizagem dos alunos com deficiência intelectual. A escola deveria ser por excelência um espaço para a construção dos saberes, respeitando o ritmo de aprendizagem de cada aluno, proporcionando seu desenvolvimento; porém, os resultados demonstram que há uma 
DOI: $10.12957 / \mathrm{e}-\mathrm{mosaicos} .2021 .51350$

busca pelo modelo de homogeneização do ensino e claramente uma falta de formação docente para atuar com alunos que não sejam neurotípicos.

Vejamos o que diz o professor de Educação Física sobre a escolarização do aluno Júlio no ensino comum:

Júlio deveria estar em uma escola especial porque eu não tenho capacitação, a secretária de Educação não me capacita, eu trabalho pela "tentativa e erro" eu penso que deveria ter alguém para ensinar para ele (CORRÊA, 2016, p. 75).

Como Júlio se apropriaria dos conceitos científicos que são próprios do ambiente escolar, se o professor nega a permanência do aluno na escola e avalia sua prática docente em tentativas e erros, porque não tem formação na área de Educação Inclusiva.

Ao referir-se às atividades escolares de Júlio na aula de Língua Portuguesa, quando o aluno fica ocioso enquanto os demais realizam a tarefa proposta pela professora, um colega de turma diz "Júlio não traz o livro para a escola porque não usa". Outro colega da turma diz que "Júlio não sabe fazer as atividades do livro porque ele é especial". Júlio é visto pelo viés da incapacidade, pela professora e por seus colegas de classe.

Vejamos o envolvimento do aluno André na atividade de Educação Física, no pátio da escola. A professora em sua aula faz um circuito para que os alunos realizem:

Animado ele entra na fila de meninos como primeiro e começa, mas ele não consegue pular com um pé só no bambolê. Então a professora vai com ele, que pisa com um pé bem devagar dentro do bambolê para depois pisar com os dois juntos neste ainda. De mãos dadas com a professora, completa o percurso (CORRÊA, 2016, p. 84).

O envolvimento do aluno na atividade ocorre quando há envolvimento docente com a mediação de forma colaborativa. Para Vigotski:

A essa colaboração original entre a criança e o adulto - momento central do processo educativo paralelamente ao fato de que os conhecimentos são transmitidos à criança em um sistema - deve-se o amadurecimento precoce dos conceitos científicos e 0 fato de que o nível de desenvolvimento desses conceitos entra na zona das possibilidades imediatas em relação aos conceitos cotidianos, abrindo-lhes caminho e 
DOI: $10.12957 / \mathrm{e}-\mathrm{mosaicos} .2021 .51350$

sendo uma espécie de propedêutica do seu desenvolvimento (VIGOTSKI, 2010, p. 244).

A respeito da aprendizagem dos alunos com deficiência intelectual, trazemos alguns dados da pesquisa de Pletsch e Oliveira (2014, p. 131) que dizem que:

A maioria dos docentes, e acrescentamos aqui os familiares, esperam respostas imediatas dos educandos. Com isso, tendem a não admitir tempos de aprendizagem (ritmos) mais lentos, o que de acordo com elas ocorre com frequência no desenvolvimento da atividade pelos estudantes com deficiência intelectual. Isso se revela em falas como "ele é muito devagar" e/ou "eu não consigo atingir ele, o ritmo é muito lento". Embora, por vezes as educadoras também afirmem que, de certa maneira, as atividades oferecidas são chatas, repetitivas e pouco significantes para o desenvolvimento cognitivo dos mesmos. Assim, podemos depreender que a complexidade da prática docente expõe não só as contradições do ambiente escolar, bem como a discrepância entre as propostas da política educacional e prática pedagógica desenvolvida nas escolas.

Logo, o progresso não imediato pode ser entendido para alguns docentes como aprendizagem insuficiente. Apenas porque aparentemente 0 resultado dessa aprendizagem não foi visto ou explicitado pelo aluno, dado a importância da apropriação conceitual na escola que caracteriza a leitura de mundo. A aprendizagem dessas questões deveria ser trabalhada em todos os cursos de licenciaturas e sempre retomados em formações continuadas, pois contribuiria para a diminuição de discriminação quanto a avaliação da aprendizagem dos alunos com deficiência intelectual.

Nessa direção, Campos (2016) aponta para o fato de que um trabalho que oportunize o desenvolvimento cognitivo e dê condições para ascender a níveis mais elevados de ensino, ainda é uma realidade a ser conquistada, especialmente em se tratando de alunos com deficiência intelectual. Contudo, o PEI em consonância com um trabalho colaborativo se torna um importante aliado, demonstrando-se fundamental para a efetivação de um processo de inclusão escolar real e justo para os alunos em questão, assim como para todos os que necessitam de apoio e suporte.

De acordo com a autora, o PEI aliado aos pressupostos da perspectiva históricocultural, possibilita caminhos para acreditar e apostar nas possibilidades e não aceitar o preestabelecimento de limites orgânicos do aluno com deficiência intelectual como impedimento. Desta maneira, contribuindo para que a escola deixe de ser o lócus da "exclusão" e passe a viver as diferenças de forma plural, produzindo e se transformando na/para a coletividade (CAMPOS, 2016). 
DOI: $10.12957 /$ e-mosaicos.2021.51350

\section{CONSIDERAÇÕES FINAIS}

Diante de toda a conjuntura política e prática sobre a formação docente na Baixada, acreditamos em uma formação continuada com vistas à autoanálise, cujo próprio professor é pesquisador da sua prática. Sendo assim, consideramos a formação continuada ação essencial à prática docente, investindo em uma educação de qualidade, com práticas pedagógicas e processo de ensino e aprendizagem que contribuam para o desenvolvimento e apropriação de conceitos pelos alunos, especialmente os alunos com deficiência intelectual.

Consideramos também a ação de desenvolvimento profissional com algo contínuo, que deve ter busca constante na medida em que o trato com seres humanos requer pesquisa assídua e o envolvimento em projetos de formação pessoal e profissional (ARAUJO, 2016). Um diálogo entre escola e universidade embasado pela perspectiva histórico-cultural, necessário par a importância da apropriação conceitual de todas as pessoas, sobretudo aquelas com deficiência intelectual.

\section{REFERÊNCIAS}

ARAUJO, D. F. de. Formação continuada de professores na perspectiva da educação inclusiva na Baixada Fluminense. 152p. Dissertação (Mestrado em Educação) Instituto de Educação / Instituto Multidisciplinar / PPGEduc / Universidade Federal Rural do Rio de Janeiro, Nova Iguaçu, RJ. 2016.

BANCO DE DADOS do ObEE. Banco de dados do grupo de pesquisa Observatório de Educação Especial e inclusão escolar: práticas curriculares e processos de ensino e aprendizagem. 2009-2016.

BRASIL. Lei Federal no 9.394, de 20 de dezembro de 1996.

. Resolução CNE/CP 1, de 18 de fevereiro de 2002.

. Lei $\mathrm{n}^{\circ} 10.436$, de 24 de abril de 2002a.

. Política Nacional de Educação Especial na perspectiva da Educação Inclusiva.

Brasília, janeiro de 2008.

. Lei $n^{\circ} 13.005$, de 25 de junho de 2014.

. Resolução $C N E / C P n^{\circ} 2$, de $1^{\circ}$ de julho de 2015. 
DOI: $10.12957 / \mathrm{e}-\mathrm{mosaicos} .2021 .51350$

. Resolução CNE/CP no 1, de 09 de agosto de 2017.

. Resolução CNE/CP no 3, de 03 de outubro de 2018.

CAMPOS, E. C. V. Z. Diálogos entre o currículo e o planejamento educacional individualizado (PEI) na escolarização de alunos com deficiência intelectual. $172 \mathrm{f}$. Dissertação (Mestrado em Educação). Universidade Federal Rural do Rio de Janeiro (UFRRJ), 2016.

CORRÊA, R. P. A formação de conceitos em alunos com deficiência intelectual: aspectos do processo de ensino e aprendizagem. 147f. Dissertação (Mestrado Profissional em Diversidade e Inclusão) - Mestrado Profissional em Diversidade e Inclusão do Departamento de Biologia do Instituto de Biologia da Universidade Federal Fluminense, Rio de Janeiro, 2016.

FICHTNER, B. Introdução na abordagem histórico-cultural de Vygotsky e seus colaboradores, 2010.

KASSAR, M. de C. M.; RODRIGUES, A. P. N.; LEIJOTO, C. P. Possibilidades e alcances dos processos de formação continuada: um estudo de caso. In: CAIADO, K. R. M.; JESUS, D. M. de; BAPTISTA, C. R. Professores e Educação Especial: formação em foco. Vol. 1. Pp. 143-158. Porto Alegre: Editora Mediação, 2011.

KOBAYASHI, D. E. do A. S.; LAPLANE, A. L. F. Perspectiva inclusiva: uma experiência de formação de professores na hora de trabalho pedagógico colaborativo. In: KASSAR, M. C. M. (Org.). Diálogos com a diversidade: desafios da formação de educadores na contemporaneidade. Mercado de Letras: Série educação geral, educação superior e formação continuada do educador. Pp. 77-92. Campinas, 2010.

KRETZSCHMAR JOENK, I. Uma Introdução ao Pensamento de Vygotsky<br>An Introduction to the Thought of Vygotsky. Revista Linhas, [S. I.], v. 3, n. 1, 2007. Disponível em: https://www.periodicos.udesc.br/index.php/linhas/article/view/1276. Acesso em: 27 abr. 2021.

MARIN, M.; BRAUN, P. Ensino colaborativo como prática de inclusão escolar. In: Glat R. e PLETSCH, M. D. Estratégias educacionais diferenciadas: para alunos com necessidades especiais. EdUERJ, 2013.

MARTINS, L. M. O desenvolvimento do psiquismo e a educação escolar: contribuições à luz da psicologia histórico-cultural e da pedagogia histórico-crítica. Campinas, SP: Autores Associados, 2013. 
DOI: $10.12957 / \mathrm{e}-\mathrm{mosaicos} .2021 .51350$

MENDES, E. G. et al. A Formação dos professores especializados segundo os pesquisadores do Observatório Nacional de Educação Especial. In: Educação e Fronteiras On-Line, Dourados/MS, v.5, n.13. Pp.151-168, maio/ago. 2015.

PLETSCH, M. D. Repensando a inclusão escolar: diretrizes políticas, práticas curriculares e deficiência intelectual. 2. Ed., ver. e ampl. Rio de Janeiro: NAU/ EDUR, 2014.

SMOLKA, A. L. B. O conhecimento e a produção de sentidos na escola: a linguagem em foco. Campinas/SP: Cortez, 2000.

VIGOTSKI, L. Interaction between learning and development (M. Lopez-Morillas, Trans.). In M. Cole, V. John-Steiner, S. Scribner, \& E. Souberman (Eds.), Mind in society: The development of higher psychological processes (pp. 79-91). Cambridge, MA: Harvard University Press. 1978.

VIGOTSKI, L. Obras escogidas IV. Madrid: Centro de Publicaciones del MEC y Visor Distribuciones. Obras escogidas V. Fundamentos de defectología. Madrid: Visor, 1997.

VIGOTSKI, L. Pensamento e Linguagem. Trad. Paulo Bezerra. - São Paulo: Martins Fontes, 2010.

Recebido em 28 de maio de 2020

Aceito em 03 de novembro de 2020

A e-Mosaicos Revista Multidisciplinar de Ensino, Pesquisa, Extensão e Cultura do Instituto de Aplicação Fernando Rodrigues da Silveira (CAp-UERJ) está disponibilizada sob uma Licença Creative Commons - Atribuição - NãoComercial 4.0 Internacional.

Os direitos autorais de todos os trabalhos publicados na revista pertencem ao(s) seu(s) autor(es) e coautor(es), com o direito de primeira publicação cedido à e-Mosaicos.

Os artigos publicados são de acesso público, de uso gratuito, com atribuição de autoria obrigatória, para aplicações de finalidade educacional e não-comercial, de acordo com o modelo de licenciamento Creative Commons adotado pela revista. 